\title{
Acute myocardial infarction in early postpartum: is it the vessel, the blood, or the plaque?
}

\author{
Irzal Hadžlbegović*, Đeiti Prvulović, Krešimir Gabaldo, Božo Vujeva \\ General Hospital "Dr J. Benčević, Slavonski Brod, Croatia
}

Acute myocardial infarction with persistent ST-segment elevation (STEMI) during early postpartum period is rare but is associated with high mortality or acute heart failure. Its incidence is greater in multigravidas older than 30 years, and it most commonly affects the anterior myocardial wall. Main causes are spontaneous coronary artery dissection, acute in-situ thrombosis due to thrombophilia, coronary vasospasm or plaque rupture. We present a case of a 31 years old multigravida who suffered an acute anterior wall STEMI 5 days after normal vaginal delivery of a healthy boy. There were no previously known cardiovascular risk factors. She was transferred to our cath-lab 2 hours after chest pain onset. Thrombotic lesion of the proximal LAD with thrombus shift in the diagonal branch was diagnosed on urgent angiogram. There were no signs of severe vasospasm or dissection. She was treated with thrombus aspiration, intracoronary and continuous intravenous eptifibatide, and balloon predilatation. Due to residual severe ostial LAD stenosis, drug eluting stent was implanted. Patient recovered well, with global left ventricular ejection fraction of $50 \%$ and mild mitral regurgitation. She had hypercholesterolemia (LDL 6.8 $\mathrm{mmol} / \mathrm{L})$. Other risk factors were not present. Laboratory and genetic tests for thrombophilia were all negative. She was without any symptoms in the follow up. We discuss coronary anatomy in early postpartum STEMI and optimal interventional and medical treatment strategy in this particular patient.

KEYWORDS: peripartum, myocardial infarction, coronary artery thrombosis.

Received: $5^{\text {th }}$ Mar 2013
*Address for correspondence: Andrije Štampara 42, HR-35000 Slavonski Brod,
Croatia.
Phone: $+385-35-201-201$
E-mail: irzal@ vip.hr

\section{Literature}

1. Roth A, Elkayam U. Acute myocardial infarction associated with pregnancy. Ann Intern Med.1996;125:751-62.

2. De Vuyst E, Preumont N, Renard M. Acute myocardial infarction in early postpartum. Acta Cardiol. 2012;67:465-7.

3. ladanza A, Del Pasqua A, Barbati R, Carrera A, Gentilini R, Favilli R, et al. Acute myocardial infarction in pregnancy due to coronary vasospasam: case report and review of literature. Int J Cardiol. 2007;115(1):81-5. 